Edição especial - Agronegócio em tempos de colapso planetário: abordagens críticas

Vol. 57, p. 199-207, jun. 2021. DOI: 10.5380/dma.v56i0.81182. e-ISSN 2176-9109

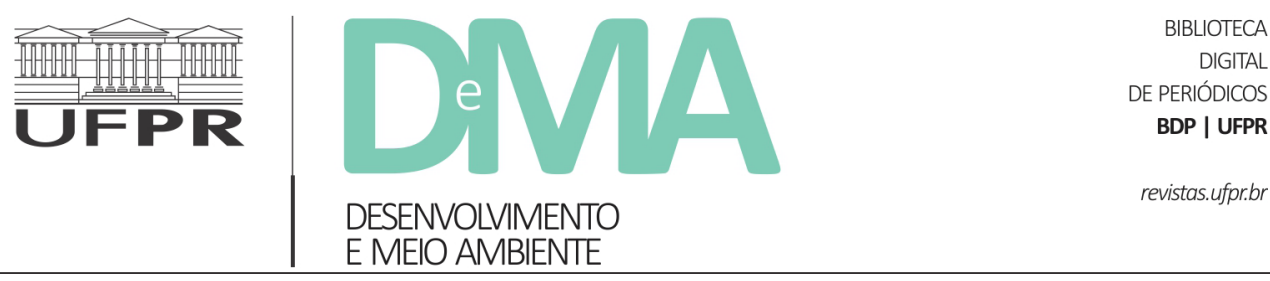

\title{
Porque a Amazônia Brasileira está em chamas
}

\section{Why the Brazilian Amazon burns}

\author{
Susanna HECHT ${ }^{1,2^{*}}$ \\ ${ }^{1}$ Instituto Universitário de Altos Estudos Internacionais, Genebra, Suíça. \\ ${ }^{2}$ Universidade da Califórnia, Los Angeles, EUA. \\ *E-mail de contato: susanna.hecht@graduateinstitute.ch
}

A Amazônia estava em chamas em agosto de 2019. Quanta floresta teve que arder a ponto de cobrir a maior megacidade do hemisfério ocidental, São Paulo, a aproximadamente 2.500 quilômetros de distância, com fumaça suficiente para escurecer completamente o céu? A área que queimava em toda a Amazônia brasileira em 2019 chegava a mais de seis milhões de hectares (cerca de 60.000 quilômetros quadrados), e outros dois milhões de hectares ardiam na Bolívia, segundo o World Wildlife Fund (WWF). O número de incêndios aumentou quase $80 \%$ em relação ao mesmo período em 2018 , de acordo com dados de sensores remotos do Instituto de Estudos Espaciais do Brasil - cujo diretor, o físico Ricardo Galvão, foi demitido por comunicar este fato diretamente ao presidente (de direita) Jair Bolsonaro.

Os habitantes de outras grandes cidades sulamericanas, desde Santa Cruz na Bolívia até o armazém de soja de Porto Velho, situado na bacia superior do rio Amazonas (no noroeste do Brasil), também respiravam ar poluído e tinham que conviver com a escuridão em pleno meio-dia. Houve uma explosão nas visitas hospitalares, incluindo muitas crianças que se tornaram asmáticas e apresentavam quadros de insuficiência respiratória.

Era difícil imaginar que a fumaça pudesse viajar tão longe e cobrir áreas tão vastas. Mas os incêndios subsequentes verificados na Austrália ao final deste mesmo ano estão no ensinando a compreender

${ }^{1}$ Tradução do original: Hecht, S. Why the Brazilian Amazon Burns. Current History, 119(814), 60-65, 2020. doi: 10.1525/curh.2020.119.814.60 
melhor as realidades inexoráveis do fogo. A fumaça proveniente desses incêndios florestais produziu uma nuvem que viajou mais de 14.000 quilômetros e agora cobre o Chile e o sul do Brasil com uma camada ainda mais saturada de fuligem. Os incêndios australianos, contudo, foram desencadeados por processos naturais e pela intensificação das alterações climáticas - com temperaturas situadas dentre as mais altas jamais registadas naquele país (48,8 graus Celsius), ventos fortes, e relâmpagos. Em contraste, os incêndios na Amazônia foram propositalmente desencadeados visando limpar áreas para especulação e uso agrícola, num surto sem precedentes de incêndios criminosos. Embora a floresta amazônica seja frequentemente queimada para controlar a regeneração de pastagens, um terço desses arroteamentos representou cerca de dois milhões de novos hectares desmatados.

As imagens chocantes dos incêndios na Amazônia ofereceram uma ilustração sombria do verão mais quente jamais registrado, e isto no segundo ano mais quente. Paris competiu com o Vale da Morte pelo local mais quente do planeta por alguns dias (43,8 graus Celsius), enquanto em Fairbanks, no Alasca, foi registrado um índice de 32,2 graus Celsius. Os incêndios na Sibéria repercutiram no Ártico, provocando o derretimento das geleiras em ritmo sem precedentes. A catástrofe foi capturada por satélites de sensoriamento remoto; os incêndios eram dramaticamente visíveis do espaço e também de drones e de fotos tiradas em terra, fazendo com que o calor se tornasse palpável.

O DNA dos ecossistemas mais complexos do planeta se transformou em meras cinzas, combinando-se com a fumaça dos incêndios florestais para formar uma nova categoria de poluição urbana e adicionar à atmosfera mais gases de efeito estufa. Plantas e animais foram reduzidos a seus constituintes químicos, deixando para trás os restos carbonizados de ambientes imolados, talvez agora perdidos para sempre. Cientistas estimam que cerca de um bilhão de animais teriam morrido nos infernos australianos. As mídias sociais foram inundadas com fotos icônicas e comoventes de coalas, wombats e cangurus emoldurados pelos cenários em chamas de seus antigos habitats florestais.

No Brasil, estudiosos e zoólogos do Instituto Nacional de Pesquisas da Amazônia (INPA), do Instituto Chico Mendes de Conservação da Biodiversidade (ICMBio, agência que administra os parques nacionais do Brasil), e do World Wildlife Fund (WWF) avaliaram os impactos dos incêndios numa das regiões do planeta dotadas de maior biodiversidade. A Amazônia brasileira abriga um número desconhecido de espécies (pelo menos 30.000) e habitats muito variados e repletos de espécies endêmicas - organismos adaptados a localidades específicas. Até o momento, ninguém poderia estimar o número total de mortes - talvez não tivessem coragem para isso - mas havia indicações de que 265 espécies estavam ameaçadas de extinção, potencialmente tornando esta temporada de incêndios um evento de aniquilação biótica definitiva.

Cientistas bolivianos estimaram que a destruição de suas florestas amazônicas, muito menos analisadas do que as brasileiras, sacrificou cerca de dois milhões de animais. No entanto, o presidente Evo Morales - que logo foi afastado devido à sua tentativa de permanecer no cargo por um quarto mandato - pronunciou-se, em agosto, sobre o primeiro embarque de carne bovina da Amazônia boliviana para a China. Seu discurso ocorreu durante um evento realizado não muito longe das raras florestas de Chiquitanía, onde naquele momento extensas porções estavam sendo queimadas até as cinzas. 
Apesar de muitas espécies terem perecido nessas tempestades de fogo, um número incalculável de outras poderão desaparecer devido à falta de alimentos, além de ferimentos e predação, enquanto vagam pelas ruínas carbonizadas de seus ecossistemas. Seria útil definir o número de vidas humanas perdidas - algumas centenas - em contraste com os vários bilhões de outros organismos que já foram sacrificados - ou que em breve poderão vir a ser devido aos incêndios.

É provável que mais casos de ecocídio já estejam a caminho. Em 2018, os cientistas Carlos Nobre e Tom Lovejoy alertaram para um ponto crítico de não retorno que emerge no horizonte, quando a Amazônia começaria a liberar seus 100 bilhões de toneladas de $\mathrm{CO}_{2}$ armazenado, ao invés de retê-los. Ela se tornaria assim uma fonte de gases geradores de efeito estufa, menos capaz de regular o clima nos níveis regional e global: o ecossistema florestal se transformará em uma paisagem mais árida, à medida que a mudança da vegetação e o aquecimento atmosférico passam a interagir num ciclo nocivo de retroalimentação. Modelizadores de ecossistemas sediados no Brasil e nos Estados Unidos já alertaram para o fato de que as mudanças climáticas e os desmatamentos vêm aumentando a vulnerabilidade das florestas do sul da Amazônia a incêndios em extensão e intensidade crescentes.

\section{O jogo de culpa de Bolsonaro}

As imagens sinistras da Amazônia em chamas desencadearam um clamor geopolítico. No entanto, o ministro do meio ambiente do Brasil, Ricardo Salles, vê as mudanças climáticas como uma "questão secundária". E o presidente Jair Bolsonaro permanece cético em relação a este cenário. Seu ministro das Relações Exteriores, Ernesto Araújo, considera este assunto uma invenção do que ele chama de propaganda "marxista cultural". Num discurso pronunciado no mês de setembro junto à Heritage Foundation, um 'Think Tank' conservador dos EUA, ele simplesmente negou que a Amazônia estivesse pegando fogo.

Qual é o significado ou o valor da proteção ambiental se você acredita no fim dos tempos, como os principais membros do ascendente movimento cristão evangélico do Brasil, ou até mesmo Bolsonaro e seu clã? O slogan de seus partidários políticos, "bíblia, boi e bala", resume parcialmente os componentes de sua coalizão: os cristãos fundamentalistas, a indústria agrícola e os militares. As agroelites brasileiras estavam perfeitamente dispostas a queimar mais de 40.000 espécies de plantas visando criar um novo habitat para apenas uma - a soja - e sacrificar um ecossistema abrigando mais de 150.000 tipos diferentes de animais (certamente uma subestimativa) para abrir espaço para uma única espécie, a vaca.

Esse comportamento destrutivo poderia nos conduzir do Antropoceno - esta nova época geológica dominada pela atividade humana - para o cenário que o biólogo E.O. Wilson denominou o Eremoceno, a Era da Solidão, já que regulamentamos extinções em massa semelhantes àquelas desencadeadas pelos impactos de asteroides que encerraram os dias dos dinossauros. Mas se você tem uma visão de mundo que apela à providência divina, pode acreditar que o mundo foi feito exclusivamente para uso dos seres humanos e para seu lucro.

No entanto, os líderes brasileiros com perfil contestador se viram de repente na defensiva. $\mathrm{Na}$ 
reunião do G7 de agosto de 2019 em Biarritz, na França, a Amazônia em chamas e as alterações climáticas irromperam na agenda. Considerando que uma reunião de cúpula sobre o clima aconteceria em Nova York em setembro, que o Vaticano sediaria um Sínodo da Amazônia em outubro, e que a reunião anual do clima das Nações Unidas já estava marcada para dezembro (o Brasil seria originalmente $\mathrm{o}$ anfitrião, mas Bolsonaro cancelou o projeto logo depois de tomar posse), os brasileiros enfrentaram a perspectiva de ter que discutir o cenário de uma possível destruição da Amazônia.

Bolsonaro entrou em ação com uma retórica tipicamente repulsiva, marcada por troca de acusações. Inicialmente, ele recusou os 22 milhões de euros em fundos de emergência oferecidos pela União Europeia, porque sentia que o presidente francês, Emmanuel Macron, o havia insultado com uma postura colonialista, ao solicitar uma discussão sobre os incêndios na Amazônia na reunião de cúpula do G7. Naquela época, os estados amazônicos lutavam por ajuda visando custear os bombeiros e o combustível necessários para que os aviões pudessem apenas lançar gotas de água simbólicas, visto que a escala dos incêndios impedia qualquer esforço significativo para controlá-los.

Em setembro, uma curta reunião de cúpula de líderes dos países amazônicos (na qual Bolsonaro não compareceu) foi organizada em Letícia, Colômbia, para discutir o problema dos desmatamentos. Mas o encontro rendeu apenas a difusão de um documento insignificante, aparentemente projetado para apaziguar a comunidade internacional e os financiadores. Nele foram oferecidos chavões sobre ajuda mútua, inovação verde, compartilhamento de informações e garantia da inclusão e consentimento dos povos indígenas nas iniciativas de desenvolvi- mento. Na verdade, nenhum país amazônico segue a lei de consentimento indígena da Organização Internacional do Trabalho (Convenção 169 da OIT), que entrou em vigor em 2016. Enquanto isso, também em setembro, Araújo e o secretário de Estado dos EUA, Mike Pompeo, anunciaram um acordo de 100 milhões de dólares para "proteger a biodiversidade" e criar oportunidades de negócios nas áreas mais remotas e inacessíveis da Amazônia - leia-se pilhagem em áreas protegidas e reservas indígenas para atender aos interesses de mineradores e madeireiros.

A equipe de Bolsonaro organizou sua campanha de troca de acusações com base numa cartilha bem ensaiada. Em primeiro lugar, Bolsonaro acusou a mídia internacional por reportagem tendenciosa destinada a prejudicar a posição do Brasil no cenário internacional. Segundo ele, o desmatamento estaria sendo apresentado como uma atividade de destruição gratuita e não como um elemento indispensável do processo de desenvolvimento do país. Ele invocou também a existência de conspirações globais, alegando que organizações não-governamentais internacionais subversivas estavam provocando incêndios e, em seguida, espalhando seus vídeos para prejudicar seu governo.

As ONGs estavam agindo assim, segundo Bolsonaro, porque a Alemanha e a Noruega congelaram 87 milhões de euros em contribuições ao Fundo Amazônia, que financia projetos para reduzir o desmatamento: mais monitoramento, ajuda na titulação, certificação ecológica, experimentos agroflorestais, pagamento pela demarcação de terras e projetos correlatos, muitos dos quais dirigidos por ONGs e movimentos sociais. Esse financiamento pode ser entendido como um pagamento amplamente definido por serviços ambientais. Sustenta 
programas de desenvolvimento que não são baseados no desmatamento. A Alemanha e a Noruega, que fornecem a maior parte do dinheiro do Fundo, decidiram suspender suas contribuições devido à estagnação das medidas de controle do desmatamento e do aumento dos ataques às instituições ambientais no Brasil.

Várias ONGs ambientais, especialmente o Greenpeace e o World Wildlife Fund, enfrentaram ameaças de que poderiam ser banidas do Brasil como organizações antigovernamentais consideradas subversivas. Em seu teatro do absurdo, Bolsonaro culpou o ator Leonardo DiCaprio e sua fundação por impulsionar a revolta popular através da coleta de fundos para a proteção ambiental. Até ONGs locais de agentes voluntários de combate aos incêndios em Alter do Chão foram acusadas de provoca-los registrando as cenas, embora essas acusações tenham sido retiradas por falta de provas. Financiamentos governamentais para ONGs nacionais, muitas das quais trabalham com povos indígenas e tradicionais, já haviam sido cortados, e aquelas que recebem recursos internacionais agora também estão sujeitas a auditoria rigorosa, por ordem de Salles emitida em janeiro de 2019. Até a rede de TV conservadora pró-Bolsonaro - Rede Globo - referiu-se a esse movimento como sendo uma "guerra contra as ONGs".

Bolsonaro e os seus aliados alegaram que os esforços para inibir o desmatamento da Amazônia mascaravam estratégias geopolíticas mais sinistras, incluindo uma trama europeia para limitar as importações de produtos agrícolas brasileiros considerados baratos, apoiando-se no acordo de comércio livre da UE com o Mercosul (o bloco econômico sul-americano), por motivos suspeitos do ponto de vista ambiental. Num registo mais sinistro, retomado da era da ditadura no Brasil, afirmaram que inibir o desmatamento tinha como objetivo condenar para sempre a nação ao subdesenvolvimento. Neste sentido, impediria que fazendeiros vinculados à agricultura industrial e produtores de soja assumissem uma posição legítima como elites hegemônicas do processo de desenvolvimento da Amazônia e fornecedores de matérias primas para mercados externos, principalmente a China. Outra retórica utilizada consistiu na advertência de que concentrar a utilização dos recursos da Amazônia em parques e áreas protegidas constituiria um pretexto para invasões estrangeiras, quando outros países tivessem esgotado os seus. À medida que a controvérsia avançava, estas questões de territorialidade e soberania tornaram-se centrais.

"A Amazônia é nossa", reitera Bolsonaro, articulando uma visão popular no meio militar, de que os ambientalistas usam os povos indígenas como fantoches para ameaçar a soberania brasileira e o modo de vida cristão, ao reivindicarem a autonomia (a autonomia indígena está inscrita na constituição de 1988). O temor é que essas "nações" nativas possam se tornar plataformas para uma invasão interna, uma espécie de "eco-foco" no sentido da terminologia revolucionária de Che Guevara. "Eles não têm lobistas e nem falam português. Como os povos indígenas acabaram detendo uma parcela tão extensa da nossa terra?" perguntou Bolsonaro em 2015, numa reunião organizada num armazém de soja de Campo Grande.

Eduardo, filho de Bolsonaro, argumentou no Congresso brasileiro que se os Estados Unidos e a Europa haviam se desenvolvido saqueando seus próprios recursos, então quem seriam eles para dizer ao Brasil o que fazer? Na verdade, imperialismo, inovação e industrialização tiveram mais a ver com o desenvolvimento dos Estados Unidos e da Europa 
do que a exploração florestal doméstica. Ambos possuem mais florestas agora do que no início do século XIX — mais de $90 \%$ das quais é nativa. Os Bolsonaros e sua comitiva, evidentemente desinformados, exortaram os líderes do G7 a mobilizar suas finanças para reflorestar seus próprios países.

Uma razão para a existência dessas florestas de zonas temperadas americanas e europeias é o desenvolvimento histórico de aparatos legais reguladores e de proteção, o manejo florestal cuidadoso e a mudança estrutural de uma economia de liquidação como a que atualmente prevalece na Amazônia. Desde o fim do regime militar, com base na constituição de 1988 e no sistema legal reformulado, o Brasil estabeleceu um sistema relativamente robusto de instituições responsáveis por desenvolver e fazer cumprir as leis ambientais nacionais, bem como as obrigações internacionais. Esses esforços, com o ativismo cidadão e iniciativas inovadoras, incluindo o monitoramento da cadeia de suprimentos e o uso de dados de compensação em tempo real para interditar crimes ambientais, reduziram o desmatamento em mais de 70\% na década de 2004 a 2014. Esperava-se realmente atingir o nível de desmatamento zero em todos os biomas do Brasil, intensificando a produção em terras subutilizadas e já desmatadas. Essa era a tendência antes da eleição de 2018 levar Bolsonaro ao poder.

\section{Evisceração de instituições}

Num nível ideológico, e também nos níveis institucional e legal, o governo de Bolsonaro preparou o cenário para o apocalipse amazônico. $\mathrm{O}$ presidente tem procurado agressivamente minar as instituições e legislações ambientais e de saúde pública, substituindo as revisões dos impactos ambientais dos projetos e legalizando a mineração e o desenvolvimento de infraestrutura em terras protegidas de povos indígenas e tradicionais. Sua abordagem de terra arrasada se assemelha ao modelo Trump nos EUA. Na verdade, Salles foi convidado a falar na sede da Agência de Proteção Ambiental dos Estados Unidos a pedido do Competitive Enterprise Institute, uma organização chefiada por Myron Ebell, a eminência parda que serviu como arquiteto para a demolição das salvaguardas ambientais pela administração Trump.

Salles dificilmente precisava de orientação sobre como arruinar uma agência ambiental. Pouco após assumir as rédeas de seu ministério, atacou o Instituto Brasileiro do Meio Ambiente (Ibama). Ele demitiu sumariamente 27 dos 29 chefes de agências regionais, substituindo-os por militares, reduziu o orçamento em mais de $24 \%$ (além dos cortes anteriores), demitiu muitos dos oficiais de campo e os proibiu de desativar equipamentos geralmente utilizados nos desmatamentos (como tratores) - uma iniciativa considerada necessária à sua interdição. O IBAMA também foi impedido de processar infratores que haviam sido multados por desmatamento ilegal. As operações no terreno foram reduzidas em cerca de $60 \%$. O ICMBio, a agência que deveria administrar as áreas protegidas, praticamente não formulou intimações de desmatamento ilegal em 2019, embora a grande extensão dos danos estivesse nitidamente visível em imagens de sensoriamento remoto.

Em 2019, numa carta amplamente difundida, os funcionários do Ibama na Amazônia relataram como tiveram que lidar com uma onda crescente de terror, incluindo ataques incendiários a seus escritórios e a destruição de seus caminhões. A 
polícia local, que costumava protegê-los em suas missões, deixou de atender aos pedidos de ajuda. $\mathrm{O}$ orçamento foi cortado tão drasticamente que quase não existe mais combustível para os caminhões que restaram, e o quadro de funcionários encontra-se exaurido em função da intensidade dos atritos e da desmoralização generalizada. Eles lamentaram que não poderiam mais continuar agindo como protetores das florestas, reconhecendo terem se tornado observadores impotentes da destruição do trabalho investido ao longo de suas vidas em consequência dos incêndios descontrolados. Essa impotência ficou mais evidente em 10 de agosto, apelidado o "Dia do Fogo", quando fazendeiros, madeireiros e outros grileiros atearam fogo nas disputadas florestas ao longo da rodovia BR-163, em desobediência às leis ambientais e às determinações do IBAMA.

Todos os ex-ministros do meio ambiente denunciaram abertamente a abordagem e as políticas adotadas por Salles, mas sem sucesso. No entanto, estripar as instituições de gestão ambiental do governo não foi suficiente. A ciência que sustentava seus programas também estava em jogo. Em uma expressão de desdém, Bolsonaro despojou o equivalente brasileiro da National Science Foundation, colocando em situação precária o distinto sistema universitário, os cientistas e os estudantes do país. As universidades estão enfrentando cortes de mais de $30 \%$ em seus orçamentos operacionais.

A política de desenvolvimento cientificamente informada para a Amazônia é a norma nas últimas décadas. As instituições que forneceram esse conhecimento foram apoiadas e expandidas mesmo sob o regime militar de 1964 a 1985. Mas sob Bolsonaro, os analistas acadêmicos viram-se em grande parte excluídos das decisões. As poucas reuniões a que compareceram estavam apinhadas de militares obedientes. O treinamento e a pesquisa dos alunos enfraqueceram, com as bolsas cortadas e as aulas canceladas.

Enquanto isso, os assessores militares que substituíram a equipe de negociações acerca das mudanças climáticas tiveram que ser informados de que o Brasil deveria sediar a reunião internacional anual. O governo cancelou, mas o episódio foi emblemático da insensatez que caracterizou esses herdeiros do que em tempos passados fora uma das joias da coroa da diplomacia brasileira, além de um marco das destacadas instituições científicas do país e de sua estatura no cenário mundial.

\section{Ateadores de fogo}

O que está desencadeando o desmatamento no Brasil? O crescimento da China impulsionou a demanda internacional por commodities, intensificada pelas tarifas impostas sobre as exportações de soja e milho dos EUA - em retaliação às tarifas do governo Trump sobre produtos chineses. Isso criou incentivos para desmatamentos, concomitantemente à ascensão política de um bloco agroindustrial que tomou a iniciativa tendo Bolsonaro como ponta de lança. As exportações agrícolas são a principal fonte de divisas do Brasil.

Durante a campanha presidencial de Bolsonaro em 2018, ele defendeu a anistia para desmatadores e ladrões de madeira, prometendo que reconheceria suas reivindicações de novas áreas desmatadas e recompensando a destruição ilegal. Ele planejava fechar o Ministério do Meio Ambiente, relaxar a fiscalização, reduzir ou eliminar o licenciamento ambiental para projetos de interesse nacional e retirar-se do acordo de Paris sobre as mudanças climáticas. 
Bolsonaro prometeu também abrir as terras dos indígenas e dos povos tradicionais da floresta para a mineração, embora seus direitos à terra estejam inscritos na constituição. Ele prometeu que a Funai, o órgão indígena, deixaria de ser autônomo e ficaria sob a égide do Ministério da Agricultura, Pecuária e Abastecimento. "Nem um centímetro de áreas protegidas, terras indígenas ou quilombos (comunidades de descendentes de escravos) será demarcado sob meu comando", gabou-se para uma multidão de apoiadores vinculados ao setor agroindustrial. O candidato esgrimiu os seus habituais chavões racistas: se os negros eram irresponsáveis e os indígenas atrasados, então por que deveriam possuir tanta terra?

Bolsonaro não cumpriu todas essas promessas desde que assumiu o cargo. Sua ousadia foi contida até mesmo para alguns membros da elite agroindustrial brasileira. Blairo Maggi, um dos maiores produtores individuais de soja do mundo, lamentou, em entrevista ao jornal Valor, que a retirada do Acordo de Paris poderia sair pela culatra e colocar em risco a participação do país nos mercados de regiões mais preocupadas com a crise ambiental como a UE, onde cadeias de commodities livres de desmatamento são cada vez mais importantes.

Mas Bolsonaro conseguiu descriminalizar a grilagem de terras, e isso explica muito do que está acontecendo agora. O método comprovado e verdadeiro é o desmatamento como meio de reivindicar terras com fraude e força, povoandoas com alguns rebanhos para mostrar que a terra está "em uso". Existem perspectivas de enormes ganhos especulativos a serem obtidos com a venda de terras assim obtidas. O sistema de criação de gado é notoriamente improdutivo (um animal por hectare) e serve principalmente para a manutenção das áreas apropriadas - em outras palavras, criando um patrimônio através da privatização de recursos públicos. Visto que geralmente são necessários alguns anos antes que as pastagens estejam prontas para serem trabalhadas na produção mecanizada de soja, as terras podem ser vendidas com elevadas margens de lucro nas fronteiras agrícolas em expansão - especialmente em antecipação aos planos de infraestrutura massiva para a Amazônia, que por sua vez são parte da iniciativa mais ampla visando a Integração da Infraestrutura Regional na América do Sul.

O governo reduziu a fiscalização, e até mesmo as revisões das licenças ambientais e de compensação, em mais de $60 \%$ em relação aos anos anteriores. Autoridades afirmaram que as áreas destinadas à criação de gado superpostas a unidades de conservação não detêm mais o status de áreas protegidas. Deveriam ser, portanto, devidamente transferidas para os pecuaristas, numa decisão que descriminaliza os desmatamentos intencionais. Combinada com uma retórica presidencial encorajadora, essa categoria de anistia oferece fortes incentivos para o desmatamento.

O desmatamento ilegal vem ocorrendo também nas reservas legais dos proprietários rurais. O código florestal indica qual a proporção de vegetação natural a ser necessariamente mantida pelo titular, incluindo margens de rios, encostas e outras categorias de áreas florestais. Estas proteções também não foram reforçadas.

Mesmo que o Ibama soubesse dessas violações, ficaria impotente para agir, como demonstrou o "Dia do Fogo" promovido em agosto nas áreas protegidas próximas à BR-163. Aqui, o antecessor de esquerda de Bolsonaro, Luiz Inácio Lula da Silva, e sua ministra do meio ambiente, Marina Silva, 
haviam instituído áreas protegidas e reservas para preservar o que se tornou basicamente um corredor de incêndio para especuladores de terras. Em agosto, aqueles que antes eram responsáveis por proteger essas florestas observavam impotentes o novo cenário - como o restante de nós. O desmatamento está agora envolto por uma nova sensação de impunidade.

O processo de desmatamento é acompanhado de muita violência porque as florestas não estão desocupadas. Pessoas vivem nelas e as utilizam. A Human Rights Watch observou em que medida o desmatamento na Amazônia tem sido terceirizado para "máfias florestais", uma inovação no complexo agroindustrial. Essas máfias operam de maneira semelhante aos serviços de gerenciamento das fazendas. Os proprietários de terras podem contratá-los para fazer uma "limpeza social": eles afugentam os agricultores locais e nativos da terra, retiram a madeira, cortam e queimam o que restou. Em contextos mais fronteiriços, milícias e atiradores simplesmente expulsam as pessoas de suas terras ou as assassinam numa cadência de aproximadamente uma por semana, de acordo com a Global Witness.

Os apologistas justificam ideologicamente esse processo violento como uma encarnação necessária e nobre da "marcha para o oeste", a versão do destino manifesto do Brasil. Mas a noção americana de destino manifesto trazia a ideia de um futuro. O Brasil de Bolsonaro simplesmente declara: AAmazônia é nossa — com ou sem futuro.
Existem alternativas e elas têm funcionado: intensificar a produção em áreas desmatadas, promover sistemas agroflorestais como açaí e cacau, desenvolver cadeias produtivas sem desmatamento, apoiar propriedades indígenas e outros guardiões da floresta em vez de assassinar seus líderes e reconhecer que os incêndios serão piores na próxima vez. E serão piores porque os outros países amazônicos - Bolívia, Peru, Equador, Colômbia e Venezuela - estão em estados de disfunção, conflito interno ou colapso, e mal conseguem governar suas capitais devido à agitação política. Mesmo que existam leis e políticas decentes, há pouca vontade política ou capacidade para aplicá-las.

A opção padrão hoje é "limpar" (remover a vegetação) para reivindicar, enquanto florestas vivas são transformadas em cinzas e ativos em todos os lugares. É assim que o patrimônio da região amazônica é manejado para compensar as práticas fracassadas de desenvolvimento, a corrupção político-econômica e a extrema desigualdade que caracterizam todos esses Estados. As políticas e parcerias entre governos e sociedade civil que mantinham as florestas em pé em muitas partes da Amazônia chegaram ao fim, pelo menos por agora. O que resta, como disse o grande escritor brasileiro Euclides da Cunha sobre a Amazônia em meio a um boom precoce de commodities impulsionado pela extração de látex, são "homens educados no cataclismo e construtores de ruínas". 